\title{
Afferent Basis of Visual Response Properties in Area MT of the Macaque. II. Effects of Superior Colliculus Removal
}

\author{
Hillary R. Rodman, ${ }^{a}$ Charles G. Gross, and Thomas D. Albright ${ }^{\mathrm{b}}$ \\ Department of Psychology, Princeton University, Princeton, New Jersey 08544
}

In a previous study (Rodman et al., 1989), we found that many neurons in the middle temporal area (MT) of the macaque monkey remain visually responsive and directionally selective after striate cortex lesions or cooling. In the present study, we examined the effects of superior colliculus (SC) lesions and combined lesions of striate cortex and the SC on the visual properties of MT neurons. Removal of the SC alone had no effect on the proportion of visually responsive cells, strength of direction selectivity and direction tuning, orientation tuning, receptive field size, or binocularity in MT. There was, however, a slight increase in response strength to both stationary and moving slit stimuli. In contrast to the minor effects of SC lesions alone, addition of an SC lesion to striate cortex damage abolished all visual responsiveness in area MT. The results indicate that pathways damaged by the SC lesion are not necessary for most of the properties of MT neurons found in the intact animal, although these pathways are capable of sustaining considerable visual responsiveness and direction selectivity when striate input is removed.

The middle temporal area (MT) of the monkey is an important locus of cortical visual motion processing and has been extensively characterized both anatomically and physiologically (e.g., Allman and Kaas, 1971; Dubner and Zeki, 1971; Zeki, 1974; Gattass and Gross, 1981; Van Essen et al., 1981; Maunsell and Van Essen, 1983a, b, c; Albright, 1984; Albright et al., 1984; Ungerleider et al., 1984; Allman et al., 1985; Ungerleider and Desimone, 1986; Rodman and Albright, 1987, 1989). In an earlier report (Rodman et al., 1989), we showed that considerable responsiveness and direction selectivity remains in MT after removal of its striate cortex input. The finding of residual responsiveness indicates an input to MT from a portion of the visual system that receives visual signals in parallel with those reaching striate cortex. Anatomical data indicate that such an

\footnotetext{
Received June 27, 1989: revised Oct. 17, 1989; accepted Oct. 30, 1989.

We wish to thank L. Kuseryk and M. Hess for work on the histology and figures and $M$. Rosengarten for word processing. We are also grateful to D. Bender for assistance with the superior colliculus lesions and to J. Maunsell for helpful discussions. Support was provided by N.I.H. grant MH-194120 and N.S.F. grant BNS-8200806.

Correspondence should be addressed to Dr. Hillary R. Rodman, Department of Neurosciences, M-008, University of California-San Diego, La Jolla, CA 92093.

Reprint requests should be addressed to Dr. Charles G. Gross, Department of Psychology, Princeton University, Princeton, NJ 08544-1010.

aresent address: Department of Neurosciences, M-008, University of California-San Diego, La Jolla, CA 92093.

b Present address: The Salk Institute for Biological Studies, P.O. Box 85800 San Diego, CA 92138.

Copyright $\odot 1990$ Society for Neuroscience $0270-6474 / 90 / 041154-11 \$ 02.00 / 0$
}

input pathway might involve the superior colliculus (SC). The superficial layers of the $\mathrm{SC}$ receive direct retinal inputs (Hubel et al., 1975; Pollack and Hickey, 1979), which potentially gain access to cortex via the pulvinar nucleus of the thalamus (e.g., Benevento and Standage, 1983). Portions of the inferior and lateral pulvinar project to MT (Maunsell and Van Essen, 1983c; Standage and Benevento, 1983), and some cells in the inferior and lateral pulvinar remain responsive in the absence of striate cortex input (Burman ct al., 1982; Bender, 1983). In addition, the sensitivity of MT neurons to stimulus motion and their relative insensitivity to stimulus form suggest a potentially important role for pathways involving the $\mathrm{SC}$ in the genesis of response properties in MT.

In the present study, we continued our investigation of the afferent basis of MT response properties by recording in MT after lesions of the SC alone and after combined lesions of striate cortex and the SC. We found that lesions of the SC alone produced only minor alterations in the characteristic properties of MT neurons. On the other hand, the residual responses seen in MT after the striate cortex lesion were abolished by the addition of an SC lesion. Some of these results have appeared briefly in abstract form (Rodman et al., 1986).

\section{Materials and Methods}

\section{Subjects}

Subjects were 4 male Macaca fascicularis weighing between 3.1 and 5.4 $\mathrm{kg}$.

SC lesions. Unilateral (left) SC lesions were made in 2 monkeys (case nos. 552 and 579). After a 1 - to 2 -week recovery period, each animal was recorded from 5 to 6 times in the space of 3-5 weeks.

Combined striate cortex-SC lesions. SC lesions were made in 2 monkeys that had previously been studied following bilateral ablation of striate cortex. The SC lesions (bilateral in case no. 555, right hemisphere only in case no. 561) were followed by a 2-week recovery period. MT was subsequently recorded from 3 to 6 times over a 2- to 4-week period in each animal.

In addition, single units in normal MT were studied with the same methods prior to the striate cortex lesion.

\section{Surgical preparation}

Access both to MT and to the SC was obtained via a 5-cm-diameter, stainless-steel chamber implanted over the midline at least 1 week prior to the SC lesion (or the initial striate cortex lesions), as described previously (Rodman et al., 1989).

SC lesions were made using methods described previously (Bender, 1983; Bruce et al., 1986). Briefly, 4 radiofrequency lesions were made in each SC, using the locations of visual receptive fields recorded on several electrode penetrations into the SC and Cynader and Berman's (1972) retinotopic map of the SC as a guide. On the day of the SC lesion, the animal was anesthetized, placed in a stereotaxic apparatus, and prepared for recording visual responses (see below). The cap of the recording chamber was removed and any tissue growth over the midline 
of the skull cleared away. A small craniotomy, centered approximately on AP-0, was made over the midline. The dura was then cut and retracted. Electrode penetrations were made vertically into the SC until its most dorsal point, where cells have receptive fields with centers at about $5^{\circ}$ along the horizontal meridian, was located. The placement of the lesions was calculated relative to the stereotaxic coordinates of this point. The lesions were produced by a Teflon-insulated stainless-steel probe with an exposed tip of $0.5 \mathrm{~mm}$ using a radiofrequency current generator (Radionics, model RFG-4). The current was passed through the probe at an intensity sufficient to heat the tip to a temperature of $74-80^{\circ} \mathrm{C}$ for $45 \mathrm{sec}$. After the lesions were made, the dura was sewn up, the cap replaced on the recording well, and the monkey allowed to recover.

The surgical methods for the striate cortex lesions have been described in Rodman et al. (1989).

\section{Recording procedure and visual stimulation}

Recording sessions were carried out under conditions of $\mathrm{N}_{2} \mathrm{O} / \mathrm{O}_{2}$ anesthesia and immobilization identical to those used in our previous studies (Albright, 1984; Rodman et al., 1989). The procedures for recording extracellular potentials from single isolated neurons or small groups of neurons were conventional and are also described fully in the above reports. The electrodes were angled $40^{\circ}$ from vertical in the parasagittal plane, passing dorsoanteriorly to ventroposteriorly before reaching MT. Single and multiunits in MT in the combined-lesion cases were tested for responsiveness with moving and flashed spots and slits of light and dark edges from a hand-held projector. Large stimuli, such as squares of cardboard, a yardstick, large brushes, etc., were also used. Responses to these stimuli were characterized as strong, weak, or absent.

For the cases with SC lesions alone, we used both hand-held stimuli and computer-assisted techniques to examine the response properties of single isolated neurons in MT. A PDP $11 / 34 \mathrm{~A}$ computer automatically controlled the presentation of stimuli by an optical bench equipped with $\mathrm{X}$ - and $\mathrm{Y}$-axis mirror galvanometers, an electronic shutter, and a stepping-motor-controlled rotation mechanism. The computer also collected spikes for peristimulus time histograms, which were displayed on-line and updated during each new trial.

Three types of stimuli were used for computer-controlled testing of MT neurons in the SC lesion cases. Moving slits of light and moving spots (single small squares) were presented at the speed estimated to be optimal on the basis of hand testing. Dimensions of the moving slit used for quantitative testing ranged from $0.5^{\circ}$ to $1.0^{\circ}$ in width and $3^{\circ}$ to $20^{\circ}$ in length; for the spot, the dimensions used ranged from $0.25^{\circ}$ to $0.5^{\circ}$ on a side. Speeds used ranged from $2 \% \mathrm{sec}$ to $64 \% \mathrm{sec}$. The slits and spots were swept approximately $30^{\circ}$ across a tangent screen along a path centered on the neuron's receptive field (RF). Each type of moving stimulus was presented in 16 directions of motion, with a constant angular deviation $\left(22.5^{\circ}\right)$ separating neighboring orientations. Stationary flashed slits, positioned in the RF so that they evoked the maximal response from a given orientation, were presented for $2.5 \mathrm{sec}$ in each of 8 orientations, with a constant angular deviation of $22.5^{\circ}$ separating neighboring orientations. For each of the 3 types of stimuli, a test consisted of a series of 5 pseudorandomly interleaved presentations of each direction or orientation. Intertrial intervals for all stimuli were a minimum of $2 \mathrm{sec}$. The above details of presentation of both moving and stationary stimuli were identical to those used for the cells studied by Albright (1984).

The sequence of testing performed on each penetration was as follows Upon entering presumptive MT cortex, we would first assess the overall sound of the cortex (spontaneous activity, burstiness) and the responsiveness and direction selectivity of the MT activity. We then proceeded to study individual neurons and, in the case of the combined lesions, small groups of cclls (multiunits). First, the responsiveness of each single or multiunit was assessed as described above. Next, for responsive recording sites, the RF was plotted using the smallest visual stimulus that would evoke a reliable response (usually a short bar of light). For the $\mathrm{SC}$ lesion cases, we next undertook, as described above, the movingslit series, followed by the moving-spot series, and then the stationaryslit series. Finally, we compared responsiveness through the contralateral and ipsilateral eyes using the scale of Hubel and Wiesel (1962).

\section{Data analysis}

As in our previous studies (Albright, 1984; Rodman and Albright, 1989), responses were considered statistically significant if they exceeded the baseline rate plus (or minus) twice its standard error. To account for asymmetries in RF dimensions, responses to moving stimuli were compensated by considering only the spike rate within a time window set to correspond to the width of the RF along its narrowest axis. Responses to moving stimuli were measured as the average rate of firing during this time window minus the spontaneous rate. Responses to stationary slits were calculated as the average rate of firing during the entire stimulus exposure minus the spontaneous rate.

\section{Histology}

The animals were killed with an overdose of intravenous sodium pentobarbital and perfused through the heart with saline followed by $10 \%$ buffered formalin. The brains were removed, blocked stereotaxically, and sectioned at $50 \mu \mathrm{m}$ in the parasagittal plane. Recording sites were reconstructed from serial sections stained with cresyl violet. The boundaries of area MT were identified in neighboring sections stained with the Gallyas (1969) silver myelin stain. The cresyl- and fiber-stained sections were also used to examine the extent of damage to the $\mathrm{SC}$ and surrounding structures. The methods for reconstructing the striate cortex lesions are described in Rodman et al. (1989).

\section{Results}

\section{Effects of SC lesions alone}

\section{Overview}

We recorded from 103 isolated single neurons in MT on a total of 23 penetrations in the hemispheres ipsilateral to the SC lesions in the 2 animals. All of these units were histologically determined to be within the myeloarchitectonic borders of MT; cclls rccorded outside of MT are not included in the present sample. Normal MT comparison data were drawn both from a sample of single units studied in MT prior to the striate lesions (for estimates of incidence of responsiveness) and from Albright (1984) (for quantitative measurements of response magnitude, selectivity, and tuning). We will first present histological verification of the SC lesions; second, we will present data on responsiveness and response strength in MT after the SC lesion; third, we will discuss direction and orientation selectivity in the sample; and fourth, we will address RF size. Finally, we will touch on a few additional characteristics of MT after SC removal, including the presence of "Type II" ("pattern-motion") neurons (Rodman and Albright, 1989).

\section{Histological findings}

Parasagittal sections through the brain stem for all the cases in the present report are shown in Figure 1. Sections from the SC lesion cases are shown on the far left (case nos. 552 and 579). On the far right (case no. 561, left hemisphere) are shown sections through the SC in an intact hemisphere for purposes of comparison; the SC and neighboring structures are labeled. Missing tissue is indicated by solid black; areas of prominent gliosis or necrotic tissue are indicated by stippling. In both cases, all layers of the $\mathrm{SC}$ were destroyed throughout virtually the entire extent of the structure. Some involvement of the medial pulvinar and pretectum was also present in each case.

\section{Responsiveness}

Figure 2 shows the incidence of strong, weak, and absent responses to the hand-held stimuli in MT after an ipsilateral SC lesion and, for comparison, in normal MT. The distributions were virtually identical $\left(\chi^{2}=2.20, d f=2, p>0.10\right)$; nearly all MT cells in both samples gave strong responses.

For each single unit responding to at least one direction of 
no. $552 R$

A

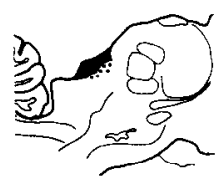

B

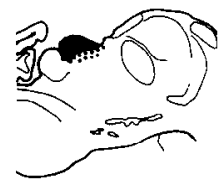

C

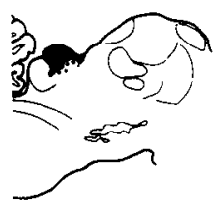

D
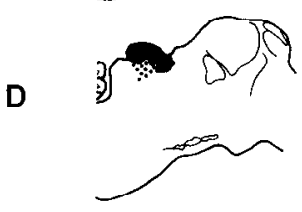

E

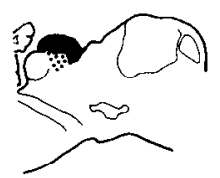

F

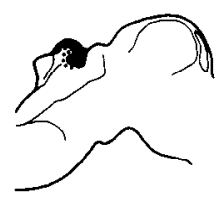
no. $579 R$

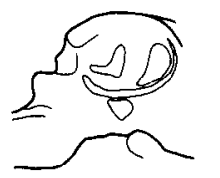

no. $555 \mathrm{R}$
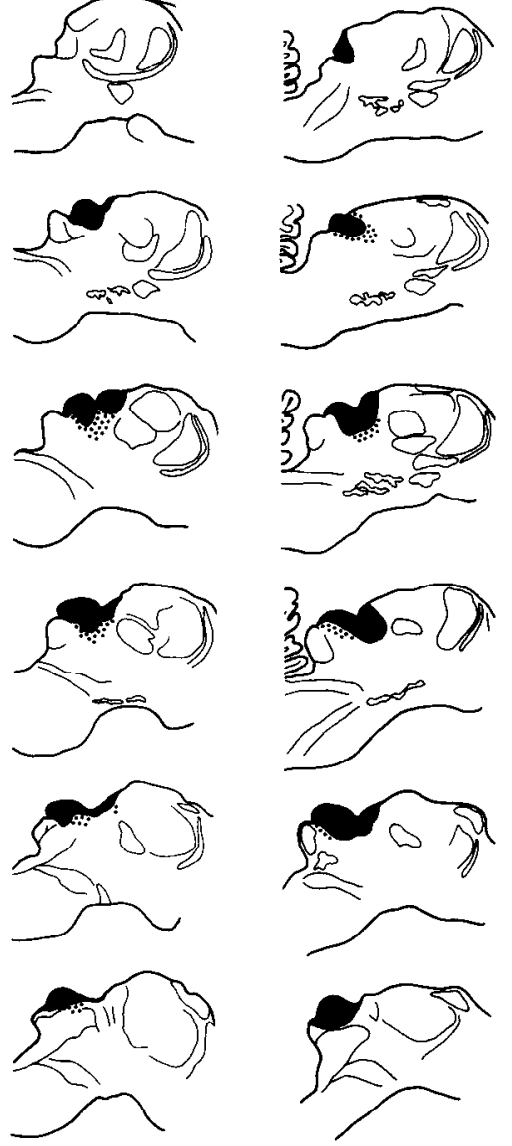

no. $555 \mathrm{~L}$

no. $561 \mathrm{R}$

no. $561 \mathrm{~L}$
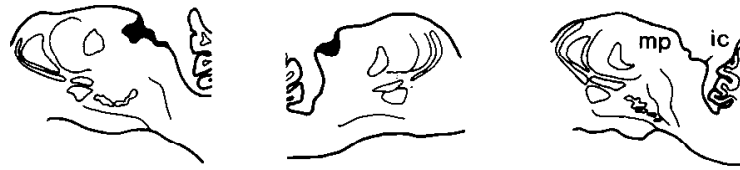

$6.0 \mathrm{La}$
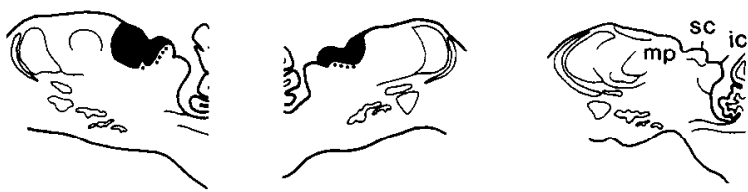

$5.0 \mathrm{La}$
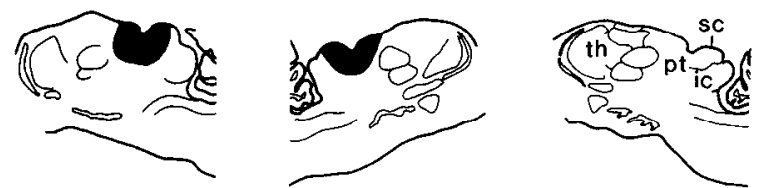

4.0 La
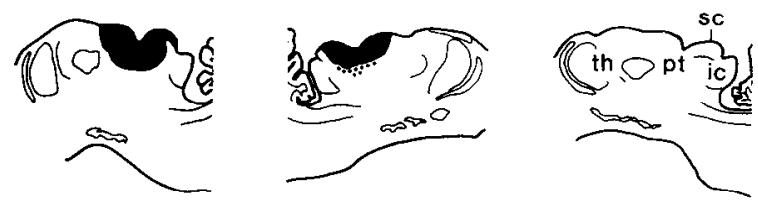

3.0 La
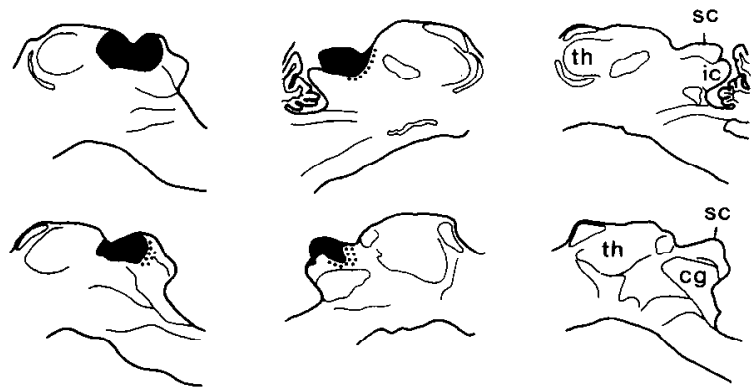

$2.0 \mathrm{La}$

$1.0 \mathrm{La}$

Figure 1. Parasagittal sections through the brain stem showing superior colliculus lesions. For purposes of comparison, the SC and neighboring structures are labeled in sections taken from an intact hemisphere (no. 561L). Missing tissue is indicated by solid black; necrotic tissue or gliosis is shown by stippling. $c g$, Central gray; $i c$, inferior colliculus; $m p$, medial pulvinar; $p t$, pretectal area; $s c$, superior colliculus; $t h$, other thalamic nuclei.

the automatically presented moving slit, we calculated a differential response magnitude measure (see Albright, 1984) as the algebraic difference between the largest and smallest deviation from baseline (spontaneous activity level) in spikes/sec. A similar procedure was used to quantify responses to the moving spot and stationary slit.

Moving stimuli. Figure 3 shows distributions of differential response magnitudes to the moving slit and moving spot for cells in MT after an SC lesion and for cells in normal MT (replotted from Albright, 1984). For both types of stimuli, there was a tendency for response magnitudes to be higher after the SC lesion than in the normal animal (moving slit: $\bar{x}=25.6 \mathrm{~s} / \mathrm{sec}$ after SC lesion vs $19.8 \mathrm{~s} / \mathrm{sec}$ in normal MT; moving spot: $\bar{x}=$ $27.9 \mathrm{~s} / \mathrm{sec}$ after $\mathrm{SC}$ lesion vs 19.0 in normal MT). The difference between the samples was significant for the moving slit (median test, $\left.\chi^{2}=5.11, d f=1, p<0.05\right)$ but not for the moving spot (median test, $\chi^{2}=3.29, d f=1, p>0.05$ ).
Stationary stimuli. Figure 4 shows distributions of differential response magnitude values for the stationary slit for cells in MT following an SC lesion and for cells in normal MT. The mean value after the SC lesion $(10.0 \mathrm{~s} / \mathrm{sec})$ was somewhat higher than that for normal MT $(5.8 \mathrm{~s} / \mathrm{sec})$, and there were significantly more high values in the post-SC distribution (median test, $\chi^{2}=7.33$, $d f-1, p<0.01)$.

\section{Direction selectivity and tuning}

Directional properties were characterized using 2 standard measures, the direction index (DI) and direction tuning bandwidth. The DI, defined as 1 - (response in antipreferred direction/ response in preferred direction), is a measure of the relative response to motion in the 2 directions along the axis of motion eliciting the best response. Distributions of this measure for the moving slit and moving spot are shown in Figure 5 for cells in MT after an SC lesion and for cells in normal MT. For both 
samples, the distributions of direction index values were clustered around 1.0 for both types of stimuli, and the samples did not differ significantly (median test) for either stimulus type. The average DI value was close to 1.0 for both samples and for both stimulus types (moving slit: $\bar{x}=0.90$ after SC lesion vs 1.0 in normal MT; moving spot: $\bar{x}=1.07$ after SC lesion vs 0.98 in normal MT), indicating an average tendency for unidirectional tuning with no response in the antipreferred direction. On the other hand, the finding of many MT neurons with DI values well over 1.0 indicates that strong inhibition to motion in the antipreferred direction was still common in MT after the SC lesion.

Direction tuning bandwidth, a measure of the sharpness of direction tuning, is defined as the width in degrees of the direction tuning curve (a plot of response as a function of direction of motion) at half of its maximum height. Figure 6 shows distributions of the direction bandwidth measure for the moving slit and moving spot for cells in MT after an SC lesion and for cells in normal MT. There was no statistical difference between the samples (median test) for either stimulus type.

\section{Orientation tuning}

Orientation tuning bandwidth (width of the orientation tuning curve at half its maximum height) was calculated for each unit that responded selectively to stationary oriented slits. The distributions of orientation tuning bandwidths found after the SC lesion and in normal MT are shown in Figure 7. There was no significant difference between the distributions.

RF size.

In normal MT, RF size increases with eccentricity in a manner that can be described with a linear function (Albright and Desimone, 1987). We plotted RF size as a function of eccentricity for MT units studied after the SC lesion and compared it to the function for units in normal MT (replotted from Albright and Desimone, 1987; Fig. 8). Regression lines fitted to each set of data are shown. There was no significant difference between the slopes of the 2 regression equations ( $t$-test for slopes). Likewise, the $y$-intercepts for the two regression lines were not significantly different ( $t$-test for intercepts).

\section{Other properties}

Binocularity. In normal MT, most neurons can be activated about equally well through either eye, and monocular units are rare (Maunsell and Van Essen, 1983b; Albright et al., 1984). The responses of 31 single units in the SC-lesioned animals were testcd for binocularity using the estimated optimal stimulus and rated according to the scale introduced by Hubel and Wiesel (1962). In this scheme, a 1 corresponds to a unit driven only through the contralateral eye, and a 7, a unit that can be driven only through the ipsilateral eye. A 4 , at the midpoint of the scale, indicates a cell that can be driven equally well through either eye. In the sample of MT neurons studied following an ipsilateral SC lesion, 30/31 had a binocularity rating of 3,4 , or 5 , indicating little or no eye dominance.

Pattern-motion cells. Movshon et al. (1985) have shown that about a quarter of MT cells are "pattern-motion selective"; that is, they respond to the motions of whole patterns independent of the motions of the constituent contours. We recently reported (Rodman and Albright, 1989) that these "pattern-motion selective" cells make up the same population as our "Type II"

\section{SC LESION}
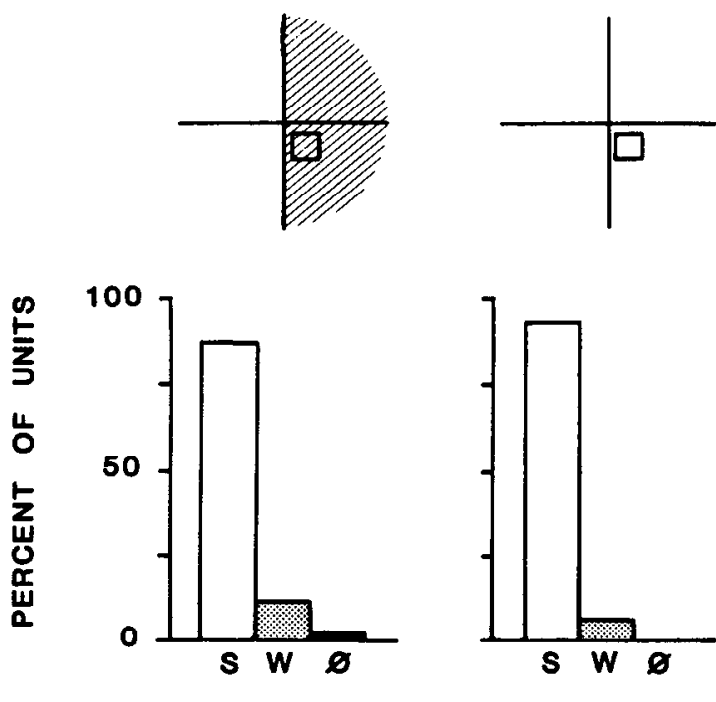

$N=103$

$\mathbf{N}=\mathbf{4 0}$

Fig. 2. Incidence of responses judged as strong, weak, or absent in MT after an ipsilateral SC lesion, and in normal MT. Hatching in diagram above graph represents lesion zone resulting from $\mathrm{SC}$ destruction relative to receptive fields in MT.

MT cells, defined as cells whose orientation preference is parallel to their preferred direction of motion (Albright, 1984). In the present study, of $24 \mathrm{MT}$ neurons in the SC lesion animals, 6 were classified as Type II. This proportion is similar to that found in normal MT (Rodman and Albright, 1989). Thus, SC lesions do not appear to alter the incidence of MT cells sensitive to the motion of whole patterns as opposed to only individual contours.

\section{Effects of combined striate cortex-SC lesions}

A total of 161 recording sites ( 89 single units and 72 multiunits) were studied on 22 penetrations into MT in the right hemispheres of the 2 animals following the combined striate cortex$\mathrm{SC}$ lesions. All of the recording sites were determined to lie within the myleoarchitectonic borders of area MT upon reconstruction of the electrode tracks.

\section{IIistological findings}

Striate cortex lesions. Reconstructions of the striate cortex lesions and ensuing lateral geniculate degeneration are shown in Rodman et al. (1989). In case no. 555, striate cortex on the dorsolateral surface of the hemisphere was removed bilaterally, resulting in a roughly circular estimated field defect (see Fig. 9, left), which extended about $4^{\circ}$ into the upper field and $6^{\circ}-8^{\circ}$ into the lower field and along the horizontal meridian. In case no. 561 , virtually all of striate cortex was removed bilaterally from the dorsolateral and medial surfaces and from within the cal- 
SC LESION

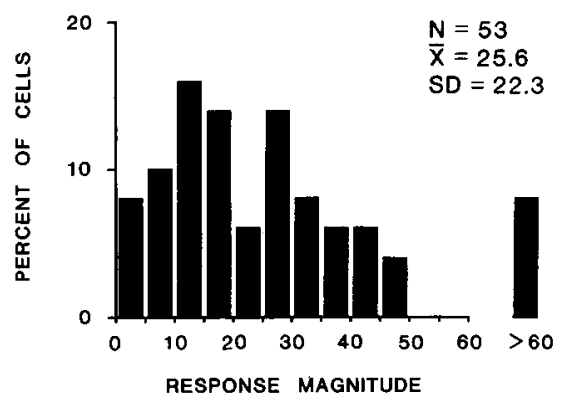

MOVING SPOT
SC LESION

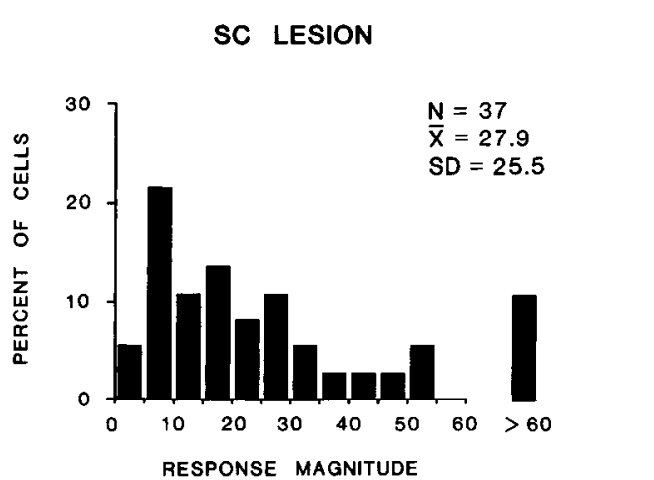

NORMAL

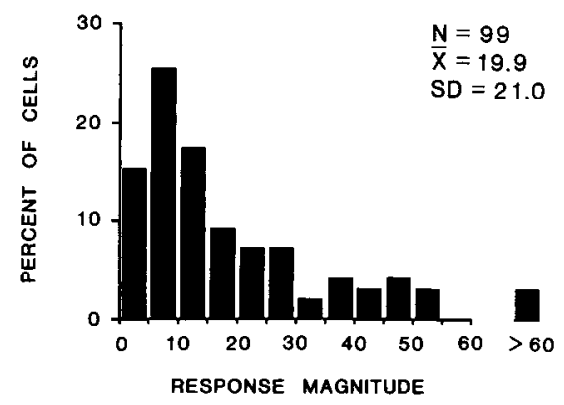

Figure 3. Distributions of differential response magnitude (algebraic difference between the largest and smallest deviation from baseline) for moving slits (top) and moving spots (bottom) for cells in MT after an SC lesion. In Figures 37 , normal MT data replotted from $\Lambda 1$ bright (1984) are shown for comparison. Dimensions and speed of motion of the stimuli used for each cell were those estimated optimal with hand testing. carine sulcus. The estimated field defect was thus total for at least the central $60^{\circ}$ (Fig. 9, right). Dorsally, the lesion extended slightly onto the posterior bank of the lunate sulcus and thus into V2 in each hemisphere. Ventrally, extrastriate damage was more extensive in the right hemisphere, involving portions of V2, V3, and cortex anteroventral to V3. Less marked involvement of the same areas was present in the left hemisphere.

$S C$ lesions. Parasagittal sections through the SC lesion for case nos. 555 and 561 are shown in Figure 1. Sections from the left hemisphere of no. 561, in which no SC lesion was made, show the location of the SC and surrounding structures in the intact midbrain. Removal of the SC of the right hemisphere of each animal was nearly complete, sparing only a small region (sections $\mathrm{C}$ and $\mathrm{D}$ ) at the posterior pole [where the far periphery is represented (Cynader and Berman, 1972)] in case no. 561. In the left hemisphere of no. 555, a larger portion of the posterior pole was spared. (However, no MT recordings were made in this hemisphere subsequent to the SC lesions.) In all 3 hemispheres with $\mathrm{SC}$ lesions in these 2 cases, there was some damage to the medial pulvinar and pretectum, as well as slight damage to the inferior colliculus.

\section{Responsiveness}

Single and multiunits in the combined lesion cases were divided into 3 categories on the basis of their RF locations relative to the estimated defect from the striate cortex lesion (see Fig. 9).
Figure 4. Distributions of differential response magnitude measure for stationary slit stimuli. See also legend to Figure 3.
SC LESION

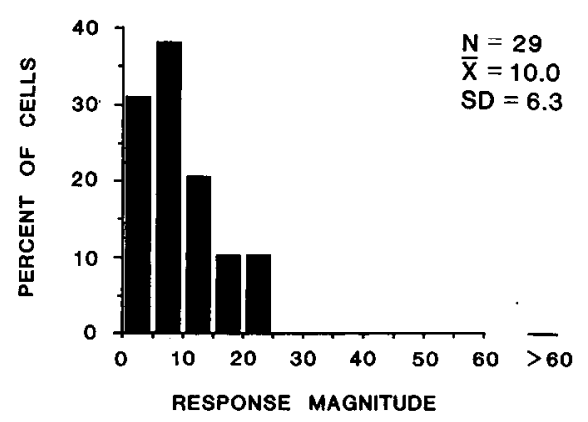

NORMAL

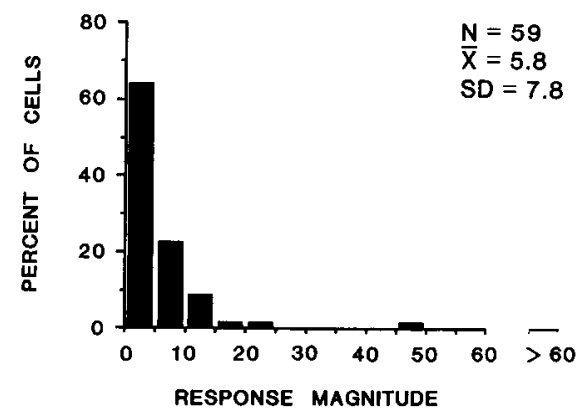




\section{MOVING SLIT}

SC LESION

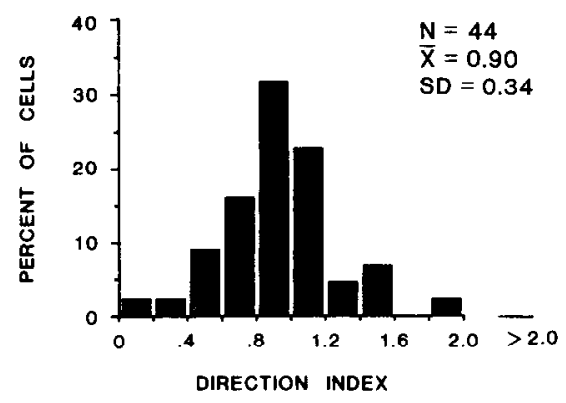

NORMAL

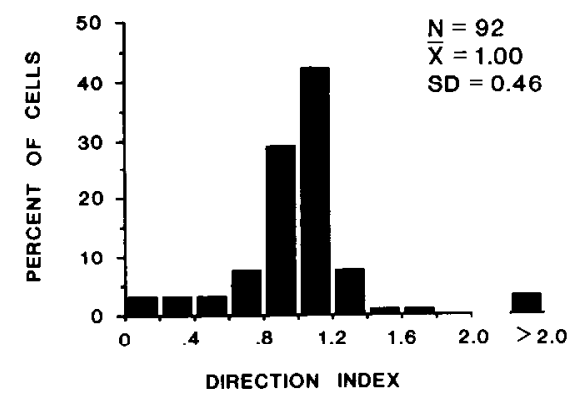

\section{MOVING SPOT}

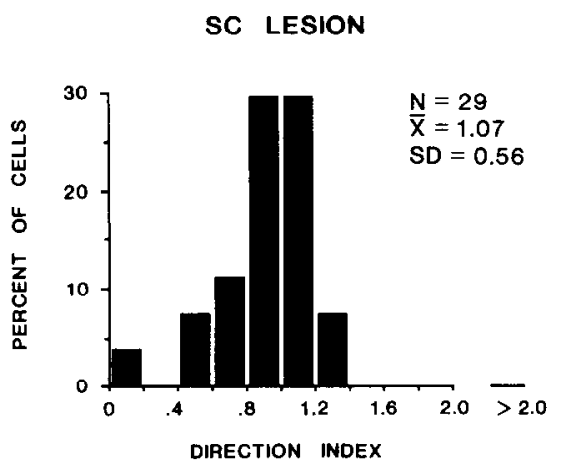

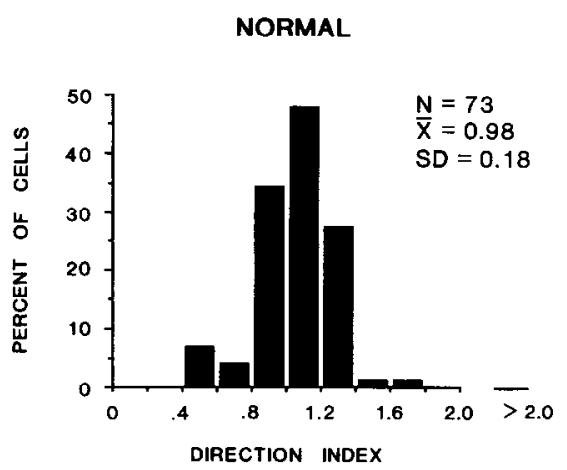

Figure 5. Distributions of direction index values for stimulation with mov. ing slits (top) and moving spots (bottom), where DI $=1$ - (response to motion in antipreferred direction/response to motion in preferred direction). See also legend to Figure 3.
Since the SC lesions were nearly total in the hemispheres recorded from, sparing only the far periphery (which part of the representation we did not study in $\mathrm{MT}$ ), all single and multiunits in the sample were presumably devoid of their ipsilateral SC input. Accordingly, units with RFs entirely within the overlap of the lesion zones reflect the effects of removal of all of both striate cortex and SC input; units with RFs partly within the overlap of the lesion zones reflect the effects of removal of all of their SC input and part of thcir striate cortex input; finally, units with RFs categorized as outside the overlap reflect only the effects of SC removal.

Since the striate cortex lesion for case no. 561 was virtually total, all single and multiunits recorded in MT in this animal fell, by definition, into the first category (entirely within the overlap of lesion zones). Thus, only units from case no. 555 fell into the second and third categories. For purposes of categorization, RFs of unresponsive single and multiunits were estimated on the basis of the fields plotted for the nearest responsive units on the same penetration, and, on penetrations with no responsive recording sites, on the basis of fields plotted on the adjacent penetrations made prior to the lesions.

Figure 10 illustrates the incidence of strong, weak, and absent responses in each of the RF categories following the combined striate cortex-SC lesions. Within the portion of MT visuotopically correspondent with the overlap of the striate cortex and SC lesions, responses were virtually absent: only 3 recording sites out of 99 tested gave even a weak response. Moreover, the background (spontaneous) activity appeared abnormal: fre- quently there was no clear cellular activity, or only a faint, rhythmic "swishing" that could be heard from the audio amplifier. Well outside the portion of the representation covered by both lesions (i.e., from which only the SC input had been removed) both the overall sound of the cortex and responses were quite normal: 17 recording sites studied in this group all were responsive, and the distribution of strong, weak, and absent responses did not differ significantly from either the normal sample or the sample of single MT units studied in the cases with SC lesions alone. The distribution of strong, weak, and absent responses for single and multiunits with RFs only partly within the overlap of the lesion zones was intermediate between the distributions for the other postlesion categories.

We did not quantitatively assess direction selectivity and binocularity after the combined lesion. However, in the course of testing responsiveness and plotting RFs in the portions of MT from which only SC input had been completely removed (i.e., where responsive units were still found), we noticed no marked change in the strength or sharpness of direction selectivity. Seven single units with RFs outside the overlap of the lesion zone tested for responsiveness through both eyes showed no clear eye dominance. These observations are consistent with the results reported in the section on the SC lesion cases.

\section{Discussion}

The results presented here show that destruction of the SC alone produces only minor alterations in the characteristic properties of neurons in visual area MT. Although there is a tendency for 


\section{MOVING SLIT}

SC LESION

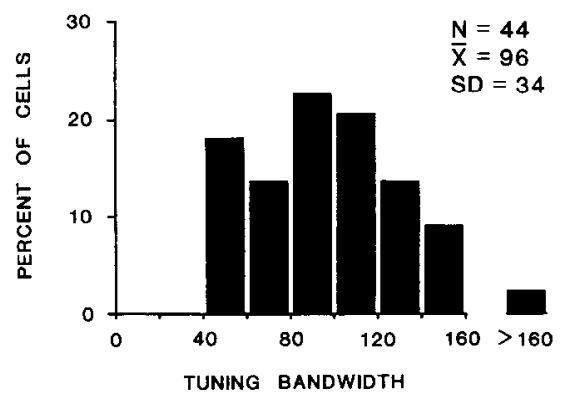

NORMAL

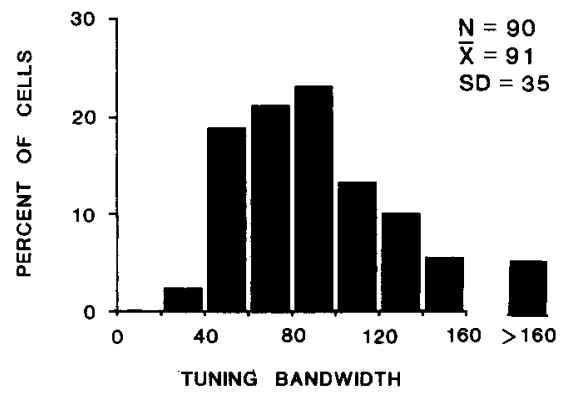

Figure 6. Distributions of direction tuning bandwidth valucs for stimulation with moving slits (top) and moving spots (bottom), where bandwidth is defined as the width of the direction tuning curve at half maximum height. See also legend to Figure 3.

\section{MOVING SPOT}

SC LESION

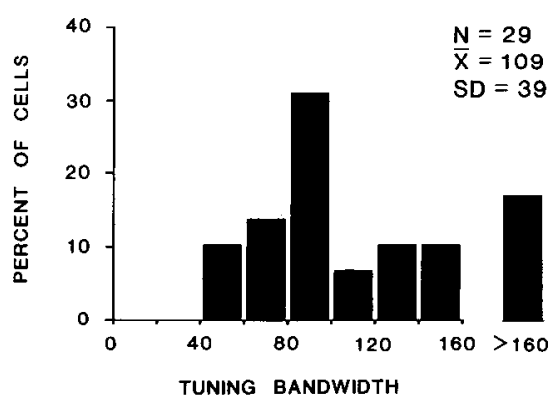

NORMAL

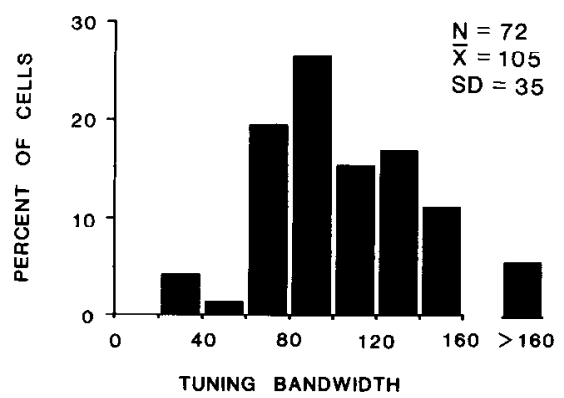

increased responsiveness to slit stimuli, there are no effects on direction selectivity or tuning, orientation tuning, RF size and other properties. As in the normal monkey, virtually all MT neurons in monkeys with SC lesions alone respond to visual stimulation. In contrast, adding an SC lesion to striate removal obliterates the considerable responsiveness remaining in MT after a striate cortex lesion.

In this section, we will first discuss the effects of SC lesions alone on response properties in the monkey visual system. Second, we will contrast the effects on neural responses and on behavior that result from damage to the $\mathrm{SC}$ with the effects of combining damage to the striate cortex and damage to the $\mathrm{SC}$. Third, we will consider in some detail the various pathways potentially interrupted by the SC lesion which may contribute to the effects of SC damage alone and in combination with a striate lesion. Finally, we will discuss implications of the findings in regard to the nature of visual area MT and known visual system organization.

\section{Effects of SC lesions alone on properties of cells in visual regions}

In the present study, SC lesions alone caused only slight changes in response magnitude to slit stimuli while leaving directional properties, RF size, incidence of responsiveness, and other characteristic MT properties intact. In the inferior pulvinar of the monkey, a region that is both a recipient of $\mathrm{SC}$ input and a source of projections to MT (Harting et al., 1980; Benevento and Standage, 1983; Maunsell and Van Essen, 1983c; Standage
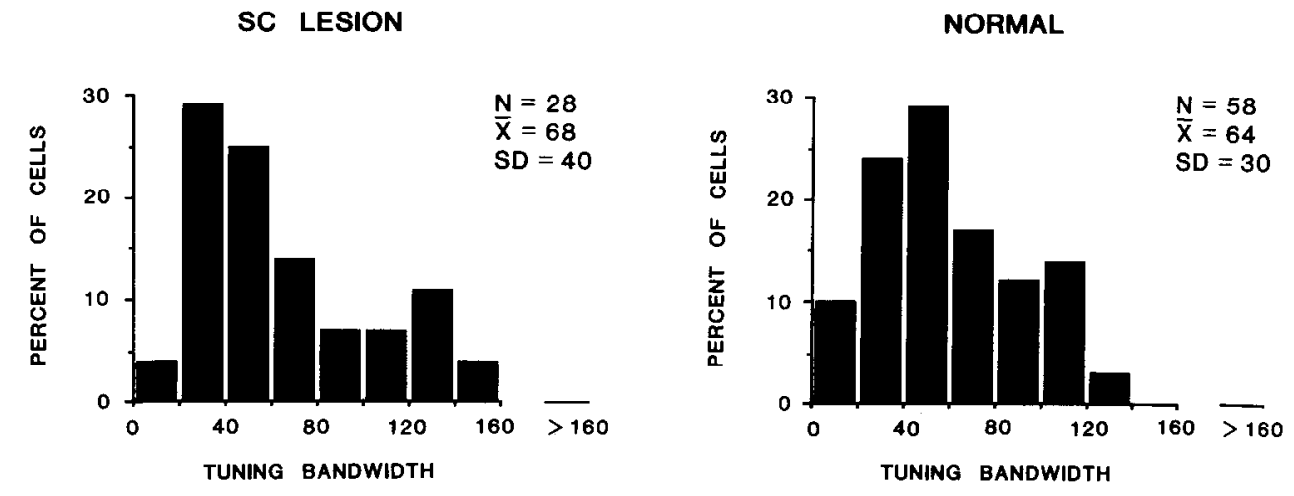

Figure 7. Distributions of orientation tuning bandwidth values for stationary slit stimuli. See also legend to Figure 3. 
SC LESION

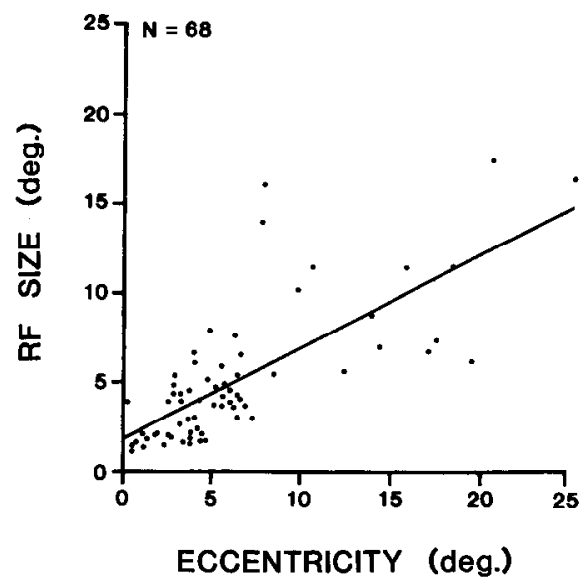

NORMAL MT

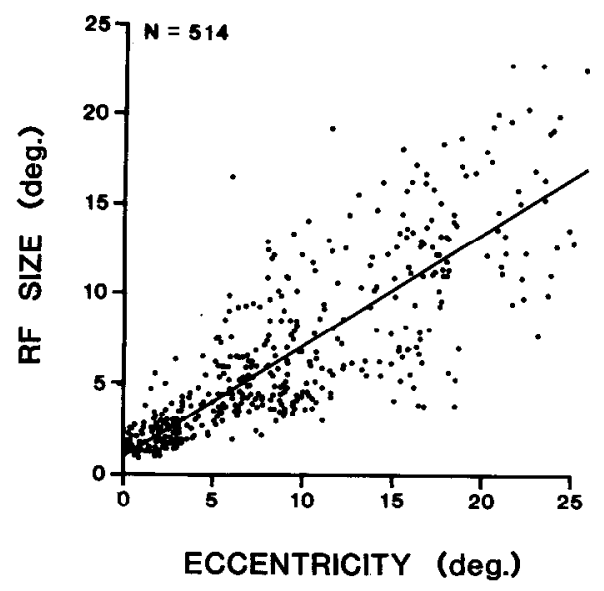

Figure 8. Plots of RF size (square root of RF area) as a function of eccentricity for cells in MT after an SC lesion and in normal MT (replotted from Albright and Desimone, 1987). Straight lines are regressions fitted to the data by the method of least squares. Slopes of rcgression lines: SC lesion, 0.51; normal MT, 0.61 . Intercepts of regression lines: SC lesion, 1.77; normal MT, 1.04 . and Benevento, 1983), Bender (1983) found similarly weak effects of SC lesions alone. Direction and orientation selectivity, RF size, and binocularity of inferior pulvinar cells were all unaffected by SC lesions. A barely significant increase in the percent of unresponsive cells was found ( $13 \%$ vs $7 \%$ in normal animals), along with an increase in the proportion of cells giving sustained responses to stationary flashed stimuli.

Bruce et al. (1986) have examined the effects of SC removal on the superior temporal polysensory area (STP) of the monkey, a primarily visual extrastriate cortical region which may receive input multisynaptically from MT via area MST (Boussaoud et al., 1987; C. Bruce, C. G. Gross, and R. Desimone, unpublished observations). The effects of SC lesions alone on STP resemble those found for MT in several respects: directional propertics of STP neurons were not affected by the SC lesions, and all neurons continued to respond to stimuli in the hemifield contralateral to the lesion. However, there were some minor differences: STP neurons became slightly more difficult to drive regardless of stimulus location or modality, and a small increase in the percent of completely unresponsive neurons was found (17\% vs $2 \%$ in intact animals). There were also slight decrements in RF size, notably a shrinking of the contralateral borders beyond about $60^{\circ}$ in the periphery. Even these weak effects seem more pronounced than those seen in MT and the pulvinar; STP may be relatively more dependent on the midbrain (including the deep, multimodal layers of the SC) for the excitability of its neurons. Moreover, STP emphasizes the peripheral visual field much more than does area MT, and the portions of STP RFs that were affected by SC lesions were in the same part of the visual field in which detection of visual stimuli is disrupted by SC damage, namely, beyond about $45^{\circ}$ (Butter et al., 1978). Since all the cells in the present study had RFs within the central $30^{\circ}$ of the visual field in MT, the possibility remains open that $\mathrm{SC}$ lesions might produce more severe effects in more peripheral MT or in parts of the caudal superior temporal sulcus representing more peripheral parts of the visual field, such as $\mathrm{MT}_{\mathrm{p}}$ (Desimone and Ungerleider, 1986).

\section{Effects of adding SC lesions to striate cortex damage}

In the present study, we found that adding an SC lesion to striate cortex damage abolished the residual responsiveness found in MT after damage to the striate cortex alone. However, SC lesions alone had only minor effects on MT responses. A similar pattern of results was found for area STP by Bruce et al. (1986): the addition of an SC lesion to existing striate cortex damage completely obliterated neuronal responses in this area, although SC lesions alone produced relatively minor changes, as described above. These sets of findings indicate that pathways damaged by the SC lesion are sufficient, but not necessary, to sustain visual responsiveness in at least 2 areas in the primate extrastriate cortex.

Lesion-behavior studies have demonstrated relatively mild effects of SC lesions in primates without concomitant striate damage. SC lesions alone produce a number of small changes in eye movements, including increased latency of saccade initiation, increased number of corrective saccades needed to fixate a target, and decrease in spontaneous saccade frequency and velocity (Mohler and Wurt7, 1977; Schiller et al., 1980, 1987). $\mathrm{SC}$ lesions in primates also produce decreases in responsiveness to peripheral stimuli (e.g., Butter et al., 1978; Albano et al., 1982) and impairments in visual search (Bender and Butter, no. 555

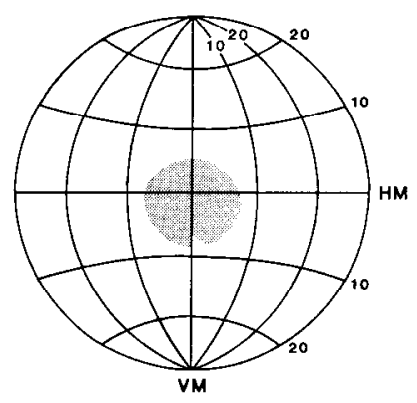

no. 561

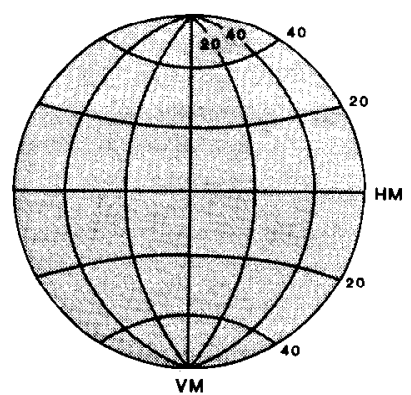

Figure 9. Estimated field defects resulting from striate cortex lesions in case no. 555 and no. 561 . In no. 555, in which only the dorsolateral surface of the occipital lobe was targeted, the field defect was small, central, and roughly circular. In no. 561 , in which we aimed to remove all of striate on the dorsolateral and medial surfaces and in the calcarine fissure, the field defect was total for at least the central $60^{\circ}$. Sections through the striate lesions and resultant LGN degeneration are shown in Rodman et al. (1989). 


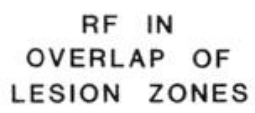
RF PARTLY IN
OVERLAP OF
LESION ZONES
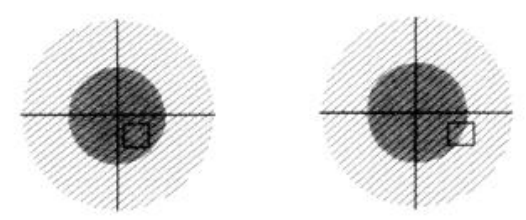

Figure 10. Incidence of responses judged as strong, weak, or absent in MT following combined striate cortex-SC lesions and in normal MT. In the schematic above each receptive field category, the shaded area represents the striate zone and the hatching, the lesion zone resulting from SC destruction. Locations of RFs of unresponsive units were estimated on the basis of those plotted on adjacent prelesion penetrations. Compare with Figure 2.
$\stackrel{\infty}{\frac{E}{z}}$

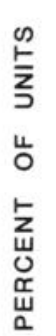
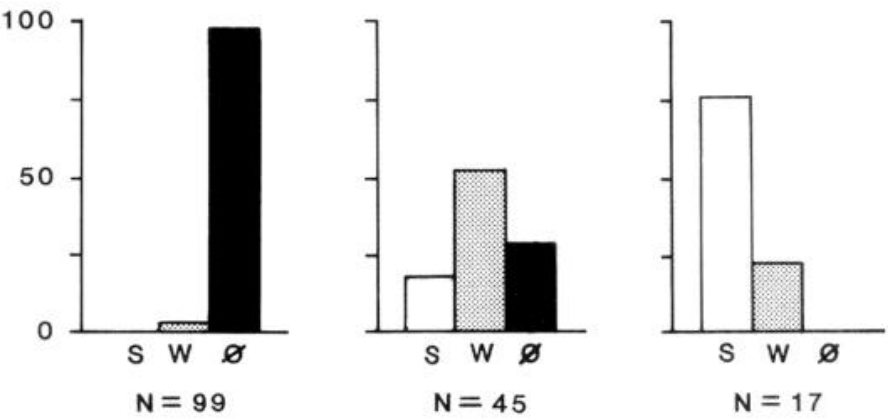

$S=S T R O N G$

RESPONSE W = WEAK
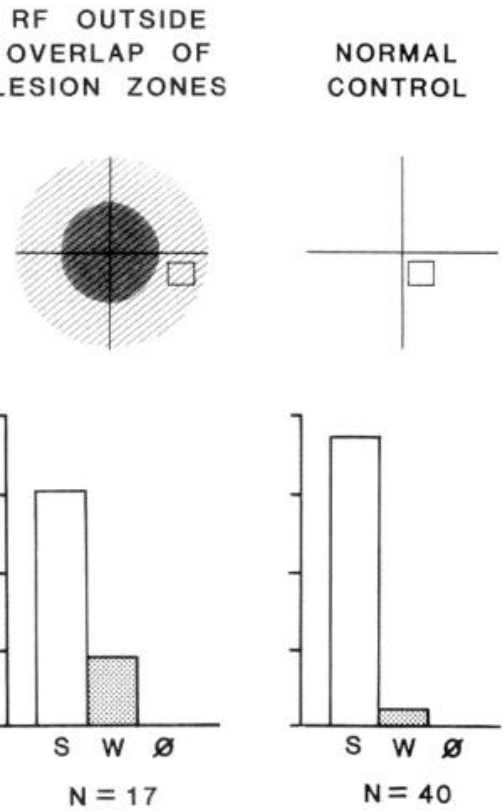

NORMAL CONTROL
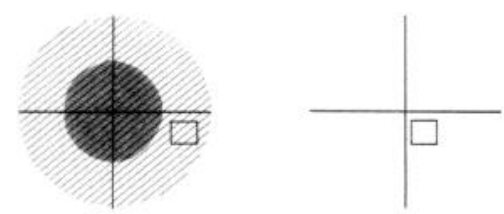

$\mathrm{N}=40$
1987). Although significant, these effects are relatively small compared to the effects of SC removal subsequent to striate ablation; the SC lesion then abolishes the recovery of visually guided behavior seen following the striate lesion in both central and peripheral parts of the visual field (Mohler and Wurtz, 1977; Solomon et al., 1981). Thus, there is a parallel between the devastating effects of combined striate-SC damage on visual cortical responses and on visual behavior.

\section{Pathways potentially damaged by SC lesions}

It is well established that in species with geniculocortical systems less well developed than those of the higher primates, the tectofugal pathways play a dominant role in visual processing (e.g., Trevarthen, 1968; Karten, 1979; Diamond et al., 1985). Because of this fact, and because of the strong, reciprocal connections of area MT with the inferior and lateral pulvinar, we have suggested (Rodman et al., 1986, 1989) that the residual responses found in MT after striate removal derive from SC inputs via the pulvinar. In support of this notion, it is well known that the superficial layers of the SC receive direct retinal input (Hubel et al., 1975; Pollack and Hickey, 1979), and these regions project to the inferior and lateral subdivisions of the pulvinar (Benevento and Fallon, 1975; Harting et al., 1980; Benevento and Standage, 1983). A small proportion of neurons in both the inferior and lateral pulvinar remain responsive after striate cortex removal (Burman et al., 1982; Bender, 1983). A pathway from the retina to MT passing through only the SC and its pulvinar targets via a minimal number of synapses is thus quite plausible. However, the portions of the inferior and lateral pulvinar that project to MT may not be the same subdivisions that receive SC input (see Kaas and Huerta, 1988). Moreover, there are several other potential routes through the midbrain and diencephalon which may be affected by SC damage and which may contribute to the effects of such damage on MT. These routes are summarized in the Appendix. In particular, the pretectum and the dorsal lateral geniculate nucleus (LGN) may play a role in the effects of SC lesions on MT responses and on visual behavior.

Potential role of the pretectum. Lesions of the SC often produce direct damage to the pretectal region, which lies just anterior to the foveal representation in the SC. Some pretectal damage was apparent in each of the cases in the present study (Fig. 1). Efferents of the pretectum go to a number of subcortical visual structures, including the SC, inferior and lateral pulvinar, and LGN (Carpenter and Pierson, 1973; Benevento et al., 1977; Benevento and Standage, 1983). Moreover, since some of these efferents pass through the brachium of the SC (Carpenter and Pierson, 1973), even lesions limited to the SC might interrupt axons en route to the pulvinar and LGN from the pretectum (Benevento and Fallon, 1975). A role for the pretectum in the visual behavior that survives striate cortex damage is suggested by the work of Pasik and Pasik (1973), who found that monkeys failed to relearn a light-no light discrimination after striate damage only when additional midbrain lesions were large and included extensive pretectal damage. Thus, it is not possible to rule out a role for the pretectum in the effects of SC damage on MT.

Potential role of the $L G N$. Although MT itself does not receive projections from any portion of the LGN (Standage and Benevento, 1981; Maunsell and Van Essen, 1983c), there are weak projections from primarily the interlaminar and magnocellular zones to extrastriate areas V4 and possibly V3 (Benevento and Yoshida, 1981; Yukie and Iwai, 1981); both these extrastriate areas project to MT (Maunsell and Van Essen, 1983c; Ungerleider and Desimone, 1986). This LGN-extrastriate pathway remains intact years after striate cortex removal (Cooper and Cowey, 1988). Two additional pieces of evidence suggest that the LGN may play a role in MT responses and in visual behavior above and beyond that serving as a relay from the retina to striate cortex. First, reversible inactivation of the magnocellular layers of the LGN produces a nearly total cessation of activity in retinotopically corresponding parts of MT (Maunsell et al., 
1989), whereas reversible inactivation of striate cortex does not (Rodman et al., 1985, 1989; Bullier and Girard, 1988). Second, lesions of the LGN abolish the visually guided eye movements that persist after striate cortex lesions (Schiller et al., 1985). Whatever role the LGN may have in the MT responses that survive striate cortex damage is obviously undermined by the SC lesion, since this lesion completely abolishes the residual responsiveness. In this regard, it is interesting that intraocular injections of amino acids label all projection structures of the LGN except extrastriate cortex (Benevento and Yoshida, 1981), suggesting that the LGN cells which project to extrastriate do not receive direct retinal input; rather, Benevento and Yoshida hypothesize that the LGN-extrastriate projection might be analogous to pulvinar-extrastriate systems which receive visual inputs from the midbrain and cortex. However, our 2 cases with minimal (no. 555) and extensive (no. 561) extrastriate damage attending striate cortex removal did not differ in sparing of MT responsiveness, arguing against an important role for the LGNextrastriate route in the remaining responses (see Rodman et al., 1989). Clearly, more work is needed to specify the role of the LGN in the visual properties of cells in MT and other extrastriate areas both in the normal monkey and in animals with visual system damage.

\section{Parallel pathways in cortex}

The residual responsiveness in MT after a striate cortex lesion is rather striking in view of the weakness of the pathways likely to be involved in relaying visual information from the midbrain to MT: as described in the previous section, only a small proportion of the cells in the lateral and inferior pulvinar remain visually responsive after the striate lesion, and none are directionally selective, and the LGN-cxtrastriatc pathway is relatively minor. Thus, MT appears able to generate a surprising amount of neural function on the basis of rather weak signals from pathways originating in the midbrain.

This relationship between MT and midbrain, moreover, may reflect the role of $\mathrm{MT}$ in spatial functions. The notion that anatomically separable pathways subserve spatial and pattern vision in primates was introduced in the 1960s (Trevarthen, 1968). In the original formulation, spatial or "ambient" functions, such as the detection and localization of brief visual stimuli, were attributed to a tectopulvinar system, whereas pattern or "focal" vision, such as the identification of objects, was attributed to geniculocortical pathways. We now know that there is a degree of separation of pathways subserving spatial and pattern vision at the cortical level (e.g., Ungerleider and Mishkin, 1982). In the current view, pattern vision is represented cortically by a pathway that originates within certain subdivisions of striate cortex, goes next to V4 via parts of V2, and then courses ventrally to areas in the inferior temporal lobe, whereas spatial vision is subserved by a pathway that originates in other compartments of striate cortex and V2 and then courses dorsally to parietal cortex via area MT and other zones within the superior temporal sulcus. Bruce et al. (1986) have suggested that while cortical areas involved in pattern vision (the ventral pathway) may be dependent solely on information deriving from geniculostriate projections, the SC may influence visual processing within the dorsal or "spatial" pathway. Major components of the dorsal, spatial vision system [namely, MT and surrounding zones in the superior temporal sulcus (Rodman et al., 1985, 1989; Bullier and Girard, 1988)] retain visual responsiveness in the absence of striate cortex input. Similarly, area STP, which receives converging input from both the dorsal and ventral cortical systems (Jones and Powell, 1970; Seltzer and Pandya, 1978, Baizer et al., 1988), contains visually responsive cells after striate lesions (Bruce et al., 1986). On the other hand, insofar as it has been examined, it appears that components of the ventral, pattern vision system (namely, V2 and inferior temporal cortex) are completely dependent on striate cortex for visual responsiveness (Rocha-Miranda et al., 1975; Schiller and Malpeli, 1977; Bullicr and Girard, 1988).

\section{Appendix}

Pathways that might provide visual input to MT and might be disrupted by SC lesions:

1. Retina $\rightarrow \mathrm{SC} \rightarrow \mathrm{P}_{\mathrm{i}}, \mathrm{P}_{1} \rightarrow \mathrm{MT}$

2. Retina $\rightarrow$ pretectum $\rightarrow \mathbf{P}_{i}, \mathbf{P}_{1} \rightarrow \mathbf{M T}$

3. Retina $\rightarrow$ pretectum $\rightarrow \mathrm{SC} \rightarrow \mathrm{P}_{\mathrm{i}}, \mathrm{P}_{1} \rightarrow \mathrm{MT}$

4. Retina $\rightarrow \mathrm{SC} \rightarrow \mathrm{LGN} \rightarrow$ extrastriate $\rightarrow \mathrm{MT}$

5. Retina $\rightarrow$ pretectum $\rightarrow$ LGN $\rightarrow$ extrastriate $\rightarrow$ MT

See text for references. Abbreviations: $\mathbf{P}_{\mathrm{i}}$, inferior pulvinar; $\mathbf{P}_{1}$, lateral pulvinar; LGN, dorsal lateral geniculate nucleus.

\section{References}

Albano, J. E., M. Mishkin, L. E. Westbrook, and R. H. Wurtz (1982) Visuomotor deficits following ablation of monkey superior colliculus. J. Neurophysiol. 48: 338-351.

Albright, T.D. (1984) Direction and orientation selectivity of neurons in visual area MT of the macaque. J. Neurophysiol. 52: 1106-1130.

Albright, T. D., and R. Desimone (1987) Local precision of visuotopic organization in the middle temporal area (MT) of the macaque. Exp. Brain Res. 65: 582-592.

Albright, T. D., R. Desimone, and C. G. Gross (1984) Columnar organization of directionally selective cells in visual area MT of the macaque. J. Neurophysiol. 51: 16-31.

Allman, J. M., and J. H. Kaas (1971) A representation of the visual field in the caudal third of the middle temporal gyrus of the owl monkey (Aotus trivirgatus). Brain Res. 31: 85-105.

Allman, J. M., F. Miezen, and E. McGuinness (1985) Stimulus-spccific responses from beyond the classical receptive field: Neurophysiological mechanisms for local-global comparisons in visual neurons. Annu. Rev. Neurosci. 8: 407-430.

Baizer, J. S., L. G. Ungerleider, and R. Desimone (1988) Organization of visual projections to parietal and temporal cortex in the macaque. Neurosci. Abstr. 14: 11.

Bender, D. B. (1983) Visual activation of neurons in the primate pulvinar depends on cortex but not colliculus. Brain Res. 279: 258261.

Bender, D. B., and C. M. Butter (1987) Comparison of the effects of superior colliculus and pulvinar lesions on visual search and tachistoscopic pattern discrimination in monkeys. Exp. Brain Res. 69: 140154.

Benevento, L. A., and J. H. Fallon (1975) The ascending projections of the superior colliculus in the rhesus monkey (Macaca mulatta). J. Comp. Neurol. 160: 339-362.

Benevento, L. A., and G. P. Standage (1983) The organization of projections of the retinorecipient and nonretinorecipient nuclei of the pretectal complex and layers of the superior colliculus to the lateral pulvinar and medial pulvinar in the macaque monkey. J. Comp. Neurol. 271: 307-336.

Benevento, L. A., and K. Yoshida (1981) The afferent and efferent organization of the lateral geniculo-prestriate pathways in the macaque monkey. J. Comp. Neurol. 203: 455-474.

Benevento, L. A., M. Rezak, and F. Santos-Anderson (1977) An autoradiographic study of the projections of the pretectum in the rhesus monkey (Macaca mulatta): Evidence for sensorimotor links to the thalamus and oculomotor nuclei. Brain Res. 127: 197-218.

Boussaoud, D., L. G. Ungerleider, and R. Desimone (1987) Cortical pathways for motion analysis: Connections of areas MST and FST in macaques. Neurosci. Abstr. 13: 1625. 
Bruce, C., R. Desimone, and C. G. Gross (1986) Both striate cortex and the superior colliculus contribute to the visual properties of neurons in the superior temporal polysensory area in the macaque. J. Neurophysiol. 5: 1057-1075.

Bullier, J., and P. Girard (1988) Visual responses of neurons in area $\mathrm{V} 2$ and in the superior temporal sulcus of the macaque monkey during reversible inactivation of area V1. Neurosci. Abstr. 14: 602.

Burman, D., G. Felsten, and L. Benevento (1982) Visual properties of neurons in the lateral pulvinar of normal and occipital lobectomized macaques. Assoc. Res. Vis. Ophthal. Suppl. 22: 237.

Butter, C. M., C. Weinstein, D. B. Bender, and C. G. Gross (1978) Localization and detection of visual stimuli following superior colliculus lesions in rhesus monkeys. Brain Res. 156: 33-49.

Carpenter, M. B. and R. J. Pierson (1973) Pretectal region and the pupiliary light reflex: An anatomical analysis in the monkey. J. Comp. Neurol. 149: 271-300.

Cooper, A. M., and A. Cowey (1988) A geniculo-prestriate projection in long-term destriate macaque monkeys. Neurosci. Abstr. 14: 1123.

Cynader, M. and N. Berman (1972) Receptive-field organization of monkey superior colliculus. J. Neurophysiol. 35: 187-201.

Desimone, R., and L. G. Ungerleider (1986) Multiple visual areas in the caudal superior temporal sulcus of the macaque. J. Comp. Neurol. 248: 164-189.

Diamond, I. T., D. Fitzpatrick, and J. M. Sprague (1985) The extrastriate visual cortex: a historical approach to the relation between "visuosensory" and "visuo-psychic" areas. In Cerebral Cortex, Vol. 4, A. Peters and E. G. Jones, eds., New York.

Dubner, R., and S. M. Zeki (1971) Response properties and receptive fields of cells in an anatomically defined region of the superior temporal sulcus in the monkcy. Brain Res. 35: 528-532.

Gallyas, F. (1969) Silver staining of myelin by means of physical development. Orvostucomany 20:433-489.

Gattass, R. G., and C. G. Gross (1981) Visual topography of the striate projection zone in the posterior superior temporal sulcus (MT) of the macaque. J. Neurophysiol. 46: 621-638.

Harting, J. K., M. F. Huerta, A. J. Frankfurter, N. L. Strominger, and G. J. Royce (1980) Ascending pathways from the monkey superior colliculus: An autoradiographic analysis. J. Comp. Neurol. 192: 853882.

Hubel, D. H., and T. N. Wiesel (1962) Receptive fields, binocular interaction and functional architecture in the cat's visual cortex. $\mathbf{J}$. Physiol. 160: 106-154.

Hubel, D. H., S. LeVay, and T. N. Wiesel (1975) Mode of termination of retinotectal fibers in macaque monkey: An autoradiographic study. Brain Res. 96: 25-40.

Jones, E. G., and T. P. S. Powell (1970) An anatomical study of converging sensory pathways within the cerebral cortex of the macaque. Brain 93: 798-820.

Kaas, J. H., and J. F. Huerta (1988) The subcortical visual system of primates. In Comparative Primate Biology, Vol. 4, H. Steklis and J. Erwin, eds., Liss, New York.

Karten, H. J. (1979) Visual lemniscal pathways in birds. In Neural Mechanisms of Behavior in the Pigeon, A. M. Granda and J. $\mathbf{H}$. Maxwell, eds., Plenum, New York.

Maunsell, J. H. R., and D. C. Van Essen (1983a) Functional properties of neurons in middle temporal visual area of the macaque monkey. I. Selectivity for stimulus direction, speed and orientation. J. Neurophysiol. 49: 1127-1147.

Maunsell, J. H. R., and D. C. Van Essen (1983b) Functional properties of neurons in middle temporal visual area of the macaque monkey. II. Binocular interactions and sensitivity to binocular disparity. J. Neurophysiol. 49: 1148-1167.

Maunsell, J. H. R., and D. C. Van Essen (1983c) The connections of the middle temporal visual area (M1) and their relationship to a cortical hierarchy in the macaque monkey. J. Neurosci. 3: 2563-2586.

Maunsell, J. H. R., D. D. DePriest, and T. A. Nealy (1989) The middle temporal visual area receives excitatory drive primarily via the magnocellular layers of the LGN. Assoc. Res. Vision Ophthal. Suppl. 30: 427.

Mohler, C. W., and R. H. Wurtz (1977) Role of striate cortex and superior colliculus in visual guidance of saccadic eye movements in monkeys. J. Neurophysiol. 40: 74-94.
Movshon, J. A., E. H. Adelson, M. S. Gizzi, and W. T. Newsome (1985) The analysis of moving visual patterns. In Study Group on Pattern Recognition Mechanisms, C. Chagas, R. G. Gattass, and C. G. Gross, eds., Pontifica Academia Scientiarum, Vatican City.

Pasik, T., and P. Pasik (1973) Extrageniculostriate vision in the monkey. IV. Critical structures for light vs. no-light discrimination. Brain Res. 56: 165-182.

Pollack, J. G., and T. L. Hickey (1979) The distribution of retinocollicular axon terminals in rhesus monkey. J. Comp. Neurol. 185: 587-602.

Rocha-Miranda, C., D. Bender, C. G. Gross, and M. Mishkin (1975) Visual activation of neurons in inferotemporal cortex depends on striate cortex and forebrain commissures. J. Neurophysiol. 38: 475491.

Rodman, H. R., and T. D. Albright (1987) Coding of visual stimulus velocity in area MT of the macaque. Vis. Res. 27: 2035-2048.

Rodman, H. R., and T. D. Albright (1989) Single-unit analysis of pattern-motion selective properties in the middle temporal visual area (MT). Exp. Brain Res. 75: 53-64.

Rodman, H. R., C. G. Gross, and T. D. Albright (1985) Removal of striate cortex does not abolish responsiveness of neurons in visual area MT of the macaque. Neurosci. Abstr. 11: 1246.

Rodman, H. R., C. G. Gross, and T. D. Albright (1986) Responses of neurons in visual area MT after removal of the superior colliculus. Neurosci. Abstr. 12:1369.

Rodman, H. R., C. G. Gross, and T. D. Albright (1989) Afferent basis of visual response properties in area MT of the macaque: I. Effects of striate cortex removal. J. Neurosci. 9: 2033-2050.

Schiller, P. H., and J. G. Malpeli (1977) The effect of striate cortex cooling on area 18 cells in the monkcy. Brain Res. 126: 366-369.

Schiller, P. H., S. True, and J. Conway (1980) Deficits in eye movements following frontal eye field and superior colliculus ablations. $\mathrm{J}$. Neurophysiol. 44: 1175-1189.

Schiller, P. H., J. H. R. Maunsell, and J. G. Malpeli (1985) The effect of lateral geniculate nucleus lesions on the detection of visual stimuli. Invest. Ophthalmol. Vis. Sci. Suppl. 26: 195.

Schiller, P. H., J. H. Sandell, and J. H. R. Maunsell (1987) The effect of frontal eye field and superior colliculus lesions on saccadic latencies in the rhesus monkey. J. Neurophysiol. 57: 1033-1049.

Seltzer, B. and D. N. Pandya (1978) Afferent cortical connections and architectonics of the superior temporal sulcus and surrounding cortex in the rhesus monkey. Brain Res. 149: 1-24.

Solomon, S. J., T. Pasik, and P. Pasik (1981) Extrageniculostriate vision in the monkey. VIII. Critical structures for spatial localization. Exp. Brain Res. 44: 259-270.

Standage, G. P., and L. A. Benevento (1981) Lack of dorsal lateral geniculate input to extrastriate cortical area MT and dorsal visual 2 in the macaque monkey. Neurosci. Abstr. 8: 680 .

Standage, G. P., and L. A. Benevento (1983) The organization of connections between the pulvinar and visual area $M T$ in the macaque monkey. Brain Res. 262: 288-294.

Trevarthen, C. (1968) Two mechanisms of vision in primates. Psychol. Forsch. 31: 299-337.

Ungerleider, L. G., and R. Desimone (1986) Cortical connections of visual area MT in the macaque. J. Comp. Neurol. 248: 190-222.

Ungerleider, L. G., and M. Mishkin (1982) Two cortical visual systems. In Analysis of Visual Behavior, D. J. Ingle, M. A. Goodale, and R. J. W. Mansfeld, eds., MIT Press, Cambridge, MA.

Ungerleider, L. G., R. Desimone, T. W. Galkin, and M. Mishkin (1984) Subcortical projections of area MT in the macaque. J. Comp. Neurol. 223: 368-386.

Van Essen, D. C., J. H. R. Maunsell, and J. L. Bixby (1981) The middle temporal visual area in the macaque: Myeloarchitecture, connections, functional properties and topographic organization. J. Comp. Neurol. 199: 293-326.

Yukie, M. and E. Iwai (1981) Direct projection from dorsal lateral geniculate nucleus to the prestriate cortex in macaque monkey. J. Comp. Neurol. 201: 81-98.

Zeki, S. M. (1974) Functional organization of a visual area in the posterior bank of the superior temporal sulcus of the rhesus monkey. J. Physiol. 236: 549-573. 